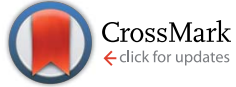

Cite this: RSC Adv., 2016, 6, 86752

\title{
Considerable Fenton and photo-Fenton reactivity of passivated zero-valent iron $\uparrow$
}

\author{
Marco Minella, ${ }^{a}$ Elisabetta Sappa, ${ }^{a}$ Khalil Hanna, ${ }^{\text {b }}$ Francesco Barsotti, ${ }^{a}$ \\ Valter Maurino, ${ }^{a}$ Claudio Minero ${ }^{a}$ and Davide Vione ${ }^{\star a}$
}

The vulnerability of Zero-Valent Iron (ZVI) to passivation, which significantly decreases its surface reactivity, limits its use as a reducing agent in environmental remediation applications (e.g., permeable reactive barriers). Passivation of $\mathrm{ZVI}$ occurs rapidly in ambient environments due to the presence of oxygen and water, as well as during the reduction of contaminants (e.g. chlorinated and nitrated organic compounds) even in anoxic conditions. Passivated zero-valent iron (pZVI) particles are typically covered by an iron (hydr)oxide layer that entails a loss of the typical properties of this material, prevents the reductive activity to take place, and could made $\mathrm{pZVI}$ a waste to be disposed of. This work shows that pZVI has considerable Fenton (oxidizing) reactivity in the presence of $\mathrm{H}_{2} \mathrm{O}_{2}$ at acidic $\mathrm{pH}$. The pZVIFenton process likely involves reaction between $\mathrm{H}_{2} \mathrm{O}_{2}$ and the pZVI surface or near-surface species, because the detected levels of leached $\mathrm{Fe}$ in the solution bulk were insufficient to account for the observed degradation processes. Still, leached $\mathrm{Fe}$ in the solution at $\mathrm{pH} 2$ and 3 would be too concentrated for some possible applications (e.g. wastewater treatment, which would require an additional precipitation step to remove excess Fe). In such a case, operation at $\mathrm{pH} 4$ would be preferred to maintain reasonable reactivity without measurable Fe leaching. The pZVI-Fenton process was inactive above $\mathrm{pH} 4$, but reactivity could be extended up to $\mathrm{pH} 5$ by UVA irradiation. Surprisingly, a pZVI sample that underwent an additional 78 day aging in aqueous solution exhibited a considerable ability to photochemically remove phenol despite a slower initial stage. These properties account for the possible use of a potential waste in decontamination reactions.

Received 8th July 2016 Accepted 31st August 2016 DOI: 10.1039/c6ra17515e www.rsc.org/advances

\section{Introduction}

Zero-valent iron (ZVI) is a strong reducing agent widely used for the reductive removal of different organic (chlorinated and nitroaromatic compounds), inorganic (chromate, arsenite and nitrate), and radioactive (uranium(vi)) pollutants. ${ }^{1-16} \mathrm{ZVI}$ is used for groundwater remediation in the form of permeable reaction barriers, ${ }^{17,18}$ or as a slurry to be injected into the contaminated aquifer. ${ }^{19}$ In the latter case, the use of a suitable dispersing agent is very important to increase the mobility of ZVI particles in the porous medium..$^{\mathbf{2 0} 21}$ Recently, ZVI has also been proposed as a reactant for the decontamination of wastewater, where it finds application towards the same contaminants that are targeted in groundwater remediation. ${ }^{18,22}$ There is growing use of ZVI technology in environmental remediation processes, due to its high reductive capacity, low cost when compared with other

${ }^{a}$ Dipartimento di Chimica, Università di Torino, Via Pietro Giuria 5, 10125 Torino, Italy. E-mail: davide.vione@unito.it; Fax: +39-011-6705242; Tel: +39-011-6705296

${ }^{b}$ Ecole Nationale Supérieure de Chimie de Rennes, CNRS, UMR 6226, 11 Allée de Beaulieu, CS 50837, 35708 Rennes Cedex 7, France. E-mail: khalil.hanna@ ensc-rennes.fr; Fax: +33-02-23238120; Tel: +33-02-23238027

$\dagger$ Electronic supplementary information (ESI) available. See DOI: 10.1039/c6ra17515e zero-valent metallic particles (e.g. bimetallic Ni-, $\mathrm{Pd}-, \mathrm{Cu}-, \mathrm{Co}^{-}$ and $\mathrm{Au}-\mathrm{Fe}^{0}$ ), the environmental friendliness of iron, and the production of non-toxic by-products. ${ }^{5,18}$

Although ZVI technologies have been extensively studied for the reduction of environmental contaminants, the rapid passivation of the ZVI surface considerably limits possible applications. In fact, ZVI particles due to their reducing power undergo a rapid surface oxidation by oxygen, as well as in $\mathrm{O}_{2}$ free aqueous solutions. Indeed, the anaerobic corrosion of ZVI in water produces ferrous ions (eqn (1)), whereas the aerobic corrosion generates ferrous ions and $\mathrm{OH}^{-}$(eqn (2)), or ferrous ions and $\mathrm{H}_{2} \mathrm{O}_{2}$ at acidic $\mathrm{pH}\left(\right.$ eqn (3)). ${ }^{23,24}$

$$
\begin{gathered}
\mathrm{Fe}^{0}+2 \mathrm{H}_{2} \mathrm{O} \rightarrow \mathrm{Fe}^{\mathrm{II}}+2 \mathrm{OH}^{-}+\mathrm{H}_{2} \\
\mathrm{Fe}^{0}+\frac{1}{2} \mathrm{O}_{2}+\mathrm{H}_{2} \mathrm{O} \rightarrow \mathrm{Fe}^{\mathrm{II}}+2 \mathrm{OH}^{-} \\
\mathrm{Fe}^{0}+\mathrm{O}_{2}+2 \mathrm{H}^{+} \rightarrow \mathrm{Fe}^{\mathrm{II}}+\mathrm{H}_{2} \mathrm{O}_{2}
\end{gathered}
$$

A further formation of $\mathrm{H}_{2} \mathrm{O}_{2}$ occurs via the oxidation of $\mathrm{Fe}^{\mathrm{II}}$ by $\mathrm{O}_{2}$ (eqn (4) and (5)), mainly at $\mathrm{pH}$ values above $6 .^{25}$

$$
\mathrm{Fe}^{\mathrm{II}}+\mathrm{O}_{2} \rightarrow \mathrm{Fe}^{\mathrm{III}}+\mathrm{O}_{2}^{-\cdot}
$$




$$
\mathrm{Fe}^{\mathrm{II}}+\mathrm{O}_{2}^{-\cdot}+2 \mathrm{H}^{+} \rightarrow \mathrm{Fe}^{\mathrm{III}}+\mathrm{H}_{2} \mathrm{O}_{2}
$$

The generated $\mathrm{H}_{2} \mathrm{O}_{2}$ can oxidize ZVI to give ferrous ions (eqn (6)) or react directly with $\mathrm{Fe}^{\mathrm{II}}$ species to promote the production of $\mathrm{OH}^{-}$at acidic $\mathrm{pH}$ according to the classic thermal Fenton reaction (eqn (7)), whereas an important formation of superoxidized iron species, such as the ferryl ion, is expected in neutral to basic conditions (eqn (8)). ${ }^{26}$ These reactions are often utilized to explain the oxidative transformation of contaminants observed in the presence of oxygen and nano-scale ZVI. $^{27,28}$

$$
\begin{gathered}
\mathrm{Fe}^{0}+\mathrm{H}_{2} \mathrm{O}_{2}+2 \mathrm{H}^{+} \rightarrow \mathrm{Fe}^{\mathrm{II}}+2 \mathrm{H}_{2} \mathrm{O} \\
\mathrm{Fe}^{\mathrm{II}}+\mathrm{H}_{2} \mathrm{O}_{2} \rightarrow \mathrm{Fe}^{\mathrm{III}} \mathrm{OH}^{2+}+\mathrm{OH}^{\cdot} \\
\mathrm{Fe}^{\mathrm{II}}+\mathrm{H}_{2} \mathrm{O}_{2} \rightarrow \mathrm{Fe}^{\mathrm{IV}} \mathrm{O}^{2+}+\mathrm{H}_{2} \mathrm{O}
\end{gathered}
$$

The surface oxidation of $\mathrm{Fe}^{0}$ is also observed during the reduction of contaminants even in anoxic environments, ${ }^{29,30}$ as for instance for nitro-compounds (eqn (9)) or halogenated compounds (eqn (10), where $\mathrm{X}$ is a halogen atom):

$$
\begin{aligned}
& 3 \mathrm{Fe}^{0}+\mathrm{R}-\mathrm{NO}_{2}+6 \mathrm{H}^{+} \rightarrow 3 \mathrm{Fe}^{\mathrm{II}}+\mathrm{R}-\mathrm{NH}_{2}+2 \mathrm{H}_{2} \mathrm{O} \\
& \mathrm{Fe}^{0}+\mathrm{RX}+\mathrm{H}^{+} \rightarrow \mathrm{Fe}^{\mathrm{II}}+\mathrm{RH}+\mathrm{X}^{-}
\end{aligned}
$$

According to reactions (1-7), precipitates composed of mixed $\mathrm{Fe}^{\mathrm{II}}-\mathrm{Fe}^{\mathrm{III}}$ and/or $\mathrm{Fe}^{\mathrm{III}}$ species may be formed as a coating layer of ZVI leading to the passivation of the surface. These species cover the surface of ZVI particles and prevent $\mathrm{Fe}^{0}$ from carrying out its typical reactions. ${ }^{31,32}$ For this reason, surface passivation becomes one of the most important issues to be overcome in order to increase the longevity or reactivity of ZVI in environmental contaminated systems. A possible approach is the depassivation/dissolution of the oxide layer coating the aged $\mathrm{Fe}^{0}$, which could for instance take place in the presence of some salts $\left(\mathrm{Cu}^{2+}, \mathrm{Co}^{2+}, \mathrm{Mn}^{2+}, \mathrm{Mg}^{2+}, \mathrm{Pb}^{2+}, \mathrm{Ni}^{2+}\right)$ and could have implications for the treatment of contaminated water in marine or otherwise highly saline environments. ${ }^{33-35}$ If, on the contrary, it is not possible to achieve depassivation, ZVI becomes unusable and a potential waste to be disposed of. This problem is relevant both to groundwater remediation, where a fast ZVI recycling is difficult and gradual passivation is almost unavoidable in normal operations, ${ }^{36}$ and to wastewater remediation, where passivation places a limit to the use of ZVI in repeated cycles. ${ }^{22,37}$ In this paper we show that passivated ZVI (hereafter, pZVI) shows important Fenton and photo-Fenton reactivity in the presence of $\mathrm{H}_{2} \mathrm{O}_{2}$. The added oxidant $\left(\mathrm{H}_{2} \mathrm{O}_{2}\right)$ could react with $\mathrm{Fe}^{\mathrm{II}}$ of the oxide coating layer of $\mathrm{ZVI}$ to generate reactive oxygen species, or with $\mathrm{Fe}^{\mathrm{III}}$ via the Haber-Weiss cycle. This finding opens up a new strategy to employ ZVI in remediation processes, in alternative to depassivation: fresh $\mathrm{ZVI}$ could be used in reduction reactions while passivated $\mathrm{ZVI}$, activated upon addition of $\mathrm{H}_{2} \mathrm{O}_{2}$, could find application in oxidative steps.

In this work, the ability of pZVI to promote Fenton and photo-Fenton reactions was assessed by using phenol as model compound because: (i) phenol is a highly studied substrate with well-known behavior in advanced oxidation processes, which makes it a first choice in the study of the oxidative reactivity of new or poorly known materials; ${ }^{38-40}$ (ii) phenol is an important component of oil refinery wastes and a by-product of the conversion of coal into gaseous or liquid fuels and of the manufacturing of metallurgical coke from coal. Therefore, phenol can occur in the environment and particularly in environmental waters because of discharges of oil refineries, coal conversion plants, municipal waste treatment plants, and spills. Phenol is highly toxic to both humans and animals, and its removal by conventional physico-chemical and biological technologies is often incomplete. ${ }^{\mathbf{4 1 , 4 2}}$ This issue accounts for the need to investigate on effective methods for phenol degradation.

\section{Experimental section}

\subsection{Reagents and materials}

Phenol (purity grade 99\%), 2-chlorophenol (99\%), 4-chlorophenol (99\%), sodium citrate (98\%), 4-aminoantipyrine (reagent grade), methanol (gradient grade), $\mathrm{H}_{3} \mathrm{PO}_{4}(85 \%)$, $\mathrm{HClO}_{4}(70 \%), \mathrm{NaCl}(99.5 \%)$ and $\mathrm{NaH}_{2} \mathrm{PO}_{4} \cdot \mathrm{H}_{2} \mathrm{O}(98 \%)$ were purchased from Aldrich, horseradish peroxidase from Sigma, sodium oxalate (99.5\%), $\mathrm{FeSO}_{4} \cdot 7 \mathrm{H}_{2} \mathrm{O}(99.5 \%), \mathrm{Fe}\left(\mathrm{NO}_{3}\right)_{3} \cdot 9 \mathrm{H}_{2} \mathrm{O}$ (98\%) and $\mathrm{H}_{2} \mathrm{SO}_{4}(96 \%)$ from Carlo Erba, $\mathrm{H}_{2} \mathrm{O}_{2}(35 \%), \mathrm{Na}_{2} \mathrm{~S}_{2} \mathrm{O}_{8}$ (98\%), KSCN (99\%) and $\mathrm{Na}_{2} \mathrm{HPO}_{4} \cdot 2 \mathrm{H}_{2} \mathrm{O}(99.5 \%)$ from VWR Int. These reagents were used as received, without further purification. Water used was of Milli-Q quality.

Passivated zero-valent iron (pZVI) was obtained by exposing a commercial ZVI sample $\left(\mathrm{Fe}^{0}\right.$ powder, 99\%, 70 mesh, $<212$ $\mu \mathrm{m}$, Acros Organics) to air over around three months, following the procedure reported in Liu et al. ${ }^{34}$ This ageing procedure passivates ZVI with a layer of mixed oxides and thus quenches its reactivity. ${ }^{34}$ In addition, some pZVI samples were further aged in aerated solutions for a variable time, which changed the visual appearance of the aqueous slurries (see below). Before and after the ageing in aerated aqueous suspension, pZVI was firstly analyzed by X-ray diffraction (XRD) with a D8 BRUKER diffractometer, and then characterized by transmission electron microscopy with selected area diffraction (TEM-SAD) (JEM-2100, JEOL).

X-ray diffraction (XRD) analysis confirmed that the pZVI sample was essentially $\mathrm{Fe}^{0}$, with a minor presence of $\mathrm{Fe}_{3} \mathrm{O}_{4}$ (magnetite) and/or $\gamma-\mathrm{Fe}_{2} \mathrm{O}_{3}$ (maghemite). Indeed, XRD data of pZVI particles (Fig. 1) revealed the presence of main peaks of $\alpha$ Fe $\left(44.6^{\circ}, 65^{\circ}\right.$ and $\left.82^{\circ} 2 \theta\right)$, and magnetite or maghemite $\left(35.3^{\circ}\right.$, $42^{\circ}$ and $57^{\circ} 2 \theta$ ). The XRD technique is unfortunately not very suitable for quantification purposes, in particular as far as the composition of the surface layer is concerned. As an alternative technique the X-ray photoelectron spectroscopy (XPS), although able to analyze the surfaces of solids, is not really suitable for a quantification (even a semi-quantitative assessment) of $\mathrm{Fe}^{\mathrm{II}}$ and $\mathrm{Fe}^{\mathrm{III}}$ species. Therefore, only a rough assessment of the pZVI surface species could be obtained here.

Transmission electron micrographs (TEM) images of the pZVI particles (Fig. 2) suggested a wide particle size 


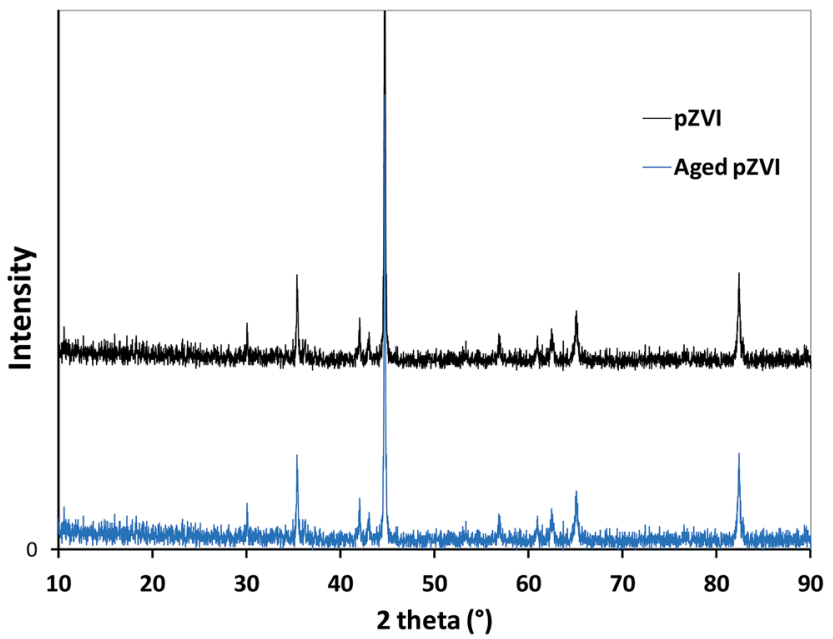

Fig. 1 XRD diffractograms showing the $\mathrm{PZVI}$ before and after ageing in $\mathrm{O}_{2}$-containing aqueous suspension for one month.

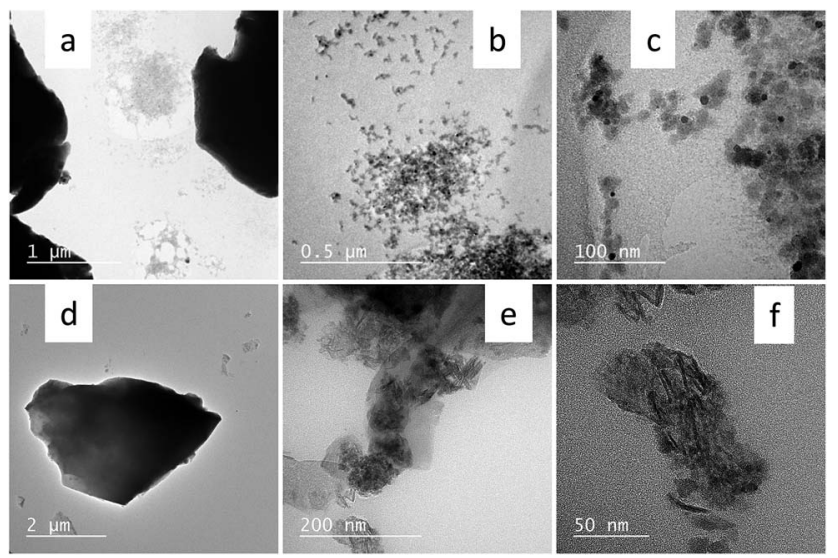

Fig. 2 TEM images showing the initial pZVI $(a-c)$ that underwent passivation in air and aged pZVI (d-f) that underwent additional ageing for one month in aerated suspension.

distribution, i.e. very small spherical particles $(\sim 20 \mathrm{~nm})$ next to bigger and shapeless particles $(\sim 2 \mu \mathrm{m})$. This finding agrees with the results of particle size distribution analysis by laser diffraction performed on the pristine commercial ZVI sample, which has suggested a very broad particle heterogeneity with an average size of around $167 \mu \mathrm{m} .^{34}$

\subsection{Phenol degradation experiments}

The solutions containing phenol (100 mL total volume) were placed in $200 \mathrm{~mL}$ beakers and were mechanically stirred. Depending on the goal of each experiment, the system could also contain pZVI and $\mathrm{H}_{2} \mathrm{O}_{2}$. The $\mathrm{pH}$ values were adjusted with $\mathrm{HClO}_{4}$. The choice of this acid is motivated by the fact that the perchlorate anion does not react significantly with ${ }^{\circ} \mathrm{OH}$, thus ensuring the absence of biases in Fenton experiments. In contrast, the anions of other mineral acids such as chloride and sulfate react with ${ }^{\circ} \mathrm{OH}$ in acidic solution (sulfate does so below $\mathrm{pH} 2$ because of the occurrence of $\mathrm{HSO}_{4}{ }^{-}$), while nitrate is a ${ }^{\circ} \mathrm{OH}$ source under irradiation. ${ }^{43}$ In some runs in the dark the $\mathrm{Fe}$ source was dissolved $\mathrm{FeSO}_{4}$ or $\mathrm{Fe}\left(\mathrm{NO}_{3}\right)_{3}$ instead of pZVI. In some experiments the beaker was irradiated with a UVA black lamp (Philips TL-D $18 \mathrm{~W}$, emission maximum at $368 \mathrm{~nm}$ ), producing an irradiance of $20.5 \mathrm{~W} \mathrm{~m}^{-2}$ on top of the irradiated systems. In all the cases, sample aliquots were taken at scheduled times from the reaction mixture and pZVI was removed by syringe filtration, using Millipore Millex HV filters $(0.45 \mu \mathrm{m}$ pore diameter). For the monitoring of phenol, $0.5 \mathrm{~mL}$ of the clear (filtered) solution were added to an HPLC vial that contained $0.5 \mathrm{~mL}$ methanol, to quench possible residual Fenton processes that might still be operational in the homogeneous phase. Analysis was carried out by liquid chromatography with diode array detection (HPLC-DAD), using a VWR-Hitachi Elite LaChrom instrument equipped with L2200 autosampler (sample volume $60 \mu \mathrm{L}$ ), L2130 quaternary pump module for lowpressure gradients, Duratec vacuum degasser, L2300 column oven (set at $40^{\circ} \mathrm{C}$ ), and $\mathrm{L} 2455$ diode-array detector. The samples were eluted with a $30: 70$ mixture of methanol and aqueous $\mathrm{H}_{3} \mathrm{PO}_{4}(\mathrm{pH} 2.8)$ at $1.0 \mathrm{~mL} \mathrm{~min}^{-1}$ flow rate, using a column Merck LiChroCART packed with LiChrospher $100 \mathrm{RP} 18(125 \mathrm{~mm} \times 4$ $\mathrm{mm} \times 5 \mu \mathrm{m}$ ). Phenol (retention time $5.7 \mathrm{~min}$, column dead time $1.2 \mathrm{~min}$ ) was monitored at $210 \mathrm{~nm}$. The repeatability of replicate experiments was about 10-20\%. Error bars are not shown on the plots for readability issues.

\subsection{Monitoring of dissolved $\mathrm{Fe}, \mathrm{H}_{2} \mathrm{O}_{2}$ and total organic carbon (TOC)}

In these determinations, methanol was not used as reaction quencher to avoid analytical biases. Therefore, care was taken to carry out the analyses soon after sampling. Dissolved Fe and its speciation were determined spectrophotometrically, ${ }^{44}$ using a Varian Cary 100 Scan double-beam, UV-Vis spectrophotometer and Hellma quartz cuvettes (1 $\mathrm{cm}$ optical path length). At selected reaction times, $15 \mathrm{~mL}$ sample aliquots were withdrawn from the reaction mixture and syringe filtered as mentioned above. For the determination of total $\mathrm{Fe}$, a $5 \mathrm{~mL}$ sub-aliquot was placed in a $10 \mathrm{~mL}$ flask and added with aqueous solutions of $\mathrm{K}_{2} \mathrm{~S}_{2} \mathrm{O}_{8}\left(0.5 \mathrm{~g} \mathrm{~L}^{-1}, 1 \mathrm{~mL}\right), \mathrm{H}_{2} \mathrm{SO}_{4}(0.1 \mathrm{M}, 1 \mathrm{~mL}), \mathrm{KSCN}\left(0.5 \mathrm{~g} \mathrm{~L}^{-1}, 1\right.$ $\mathrm{mL}$ ), and with water to volume. In this way, dissolved $\mathrm{Fe}^{\mathrm{II}}$ was oxidized to $\mathrm{Fe}^{\mathrm{III}}$ by $\mathrm{S}_{2} \mathrm{O}_{8}{ }^{2-}$, and total $\mathrm{Fe}$ could be quantified as $\mathrm{FeSCN}^{2+}$ at $457 \mathrm{~nm}$. $\mathrm{Fe}$ (III) was determined on a further $5 \mathrm{~mL}$ sub-aliquot in a similar way, but without addition of $\mathrm{K}_{2} \mathrm{~S}_{2} \mathrm{O}_{8}$. The concentration of $\mathrm{Fe}^{\mathrm{II}}$ was obtained as the difference between total $\mathrm{Fe}$ and $\mathrm{Fe}^{\mathrm{III}}$. Under these conditions, the $\mathrm{Fe}$ detection limit was $0.05 \mathrm{mg} \mathrm{Fe} \mathrm{L}^{-1}$.

Hydrogen peroxide was also determined spectrophotometrically, using the peroxidase-4-aminoantipyrine method. ${ }^{45}$ The color-forming reagent was prepared by dissolving $0.10 \mathrm{~g} \mathrm{4-}$ aminoantipyrine, $0.23 \mathrm{~g}$ phenol, $1 \mathrm{mg}$ horseradish peroxidase, $0.71 \mathrm{~g} \mathrm{NaH}_{2} \mathrm{PO}_{4}$ and $0.28 \mathrm{~g} \mathrm{Na}_{2} \mathrm{HPO}_{4}$ in $100 \mathrm{~mL}$ water. Sample aliquots for $\mathrm{H}_{2} \mathrm{O}_{2}$ monitoring $(10 \mathrm{~mL})$ were withdrawn from the reaction mixture and filtered. In each $10 \mathrm{~mL}$ flask it was placed a filtered sample sub-aliquot of 0.5 to $5 \mathrm{~mL}, 4 \mathrm{~mL}$ reagent and water to volume. The volume of filtered sample added in each case was determined with the aims of carrying out the measure 
within the linearity range of the method $\left(0.05-0.25 \mathrm{mM} \mathrm{H}_{2} \mathrm{O}_{2}\right)$ and of maximizing the sensitivity of the whole analytical procedure, avoiding unnecessary dilution of the sample. The colored adduct between oxidized phenol and 4-aminoantipyrine was detected at $505 \mathrm{~nm}$.

To monitor the TOC, $15 \mathrm{~mL}$ sample aliquots were withdrawn at scheduled times, filtered and injected into a Shimadzu TOCV-CSH total organic carbon analyzer. The TOC was determined as the difference between total carbon and inorganic carbon.

\section{Results and discussion}

The inability of the pZVI material to act as an effective reducing agent was tested towards the dechlorination of 2- and 4-chlorophenol, which yield phenol and chloride ions upon reduction in the presence of ZVI. ${ }^{46-49}$ Attempts aimed at achieving surface depassivation, by addition of ligands for $\mathrm{Fe}$ ions such as oxalate and citrate, or with a combination of ligands and irradiation (with the purpose of dissolving the iron oxide layer ${ }^{50}$ and allowing the underlying $\mathrm{Fe}^{0}$ to get in contact with the solution) were not successful and no dechlorination of either 2- or 4chlorophenol was observed. However, pZVI proved to be effective in inducing the Fenton reaction in the presence of $\mathrm{H}_{2} \mathrm{O}_{2}$. The rest of this work is devoted to the study of the Fenton and photo-Fenton reactivity of pZVI under a variety of conditions.

\subsection{Fenton reactivity of pZVI}

3.1.1. Effect of $\mathbf{p H}$. The classical, homogeneous Fenton reaction has an optimum $\mathrm{pH}$ around 3, largely because under these conditions the $\mathrm{Fe}^{\mathrm{III}}$ species generated in reaction (7) are mainly in the form of $\mathrm{FeOH}^{2+}$, which undergoes relatively fast recycling to $\mathrm{Fe}^{2+}$ upon reaction with $\mathrm{H}_{2} \mathrm{O}_{2}$ and $\mathrm{HO}_{2} \cdot{ }^{\cdot 51}$ Moreover, changing $\mathrm{pH}$ also modifies the nature of the main Fenton oxidant, from ${ }^{\circ} \mathrm{OH}$ that prevails in acidic solutions to less reactive ferryl species that play the predominant role under $\sim$ neutral conditions (eqn (8))..$^{52-54}$ In the case of heterogeneous Fenton processes, the $\mathrm{pH}$ value might also affect the leaching of Fe from oxide coating surfaces. ${ }^{55,56}$

The effect of $\mathrm{pH}$ on the Fenton degradation of phenol induced by pZVI is shown in Fig. 3. The process was fastest at $\mathrm{pH} 3$ and became ineffective at $\mathrm{pH} \geq 5$. Interestingly, in the optimal pH conditions a complete disappearance of phenol was observed in less than 10 min reaction time. The reported $\mathrm{pH}$ trend is not much different from that observed in the homogeneous phase, ${ }^{57,58}$ but it does not make conclusive evidence in favor of the site(s) where the Fenton reaction takes place (involving either dissolved $\mathrm{Fe}$ or Fe-sites on or near the pZVI surface, vide infra).

3.1.2. Effect of $\mathrm{H}_{2} \mathrm{O}_{2}$ concentration. Hydrogen peroxide is essential for the Fenton reaction, but it can also act as a scavenger of reactive species. ${ }^{59,60}$ Therefore, it is important to investigate on the $\mathrm{H}_{2} \mathrm{O}_{2}$ concentration that maximizes the process efficiency. In the present work, this test was carried out at the optimum $\mathrm{pH}$ for pZVI-Fenton ( $\mathrm{pH} 3)$. First of all, very limited to nil degradation of phenol was observed in the absence of $\mathrm{H}_{2} \mathrm{O}_{2}$ (see Fig. 4). Fresh ZVI should be able to induce,

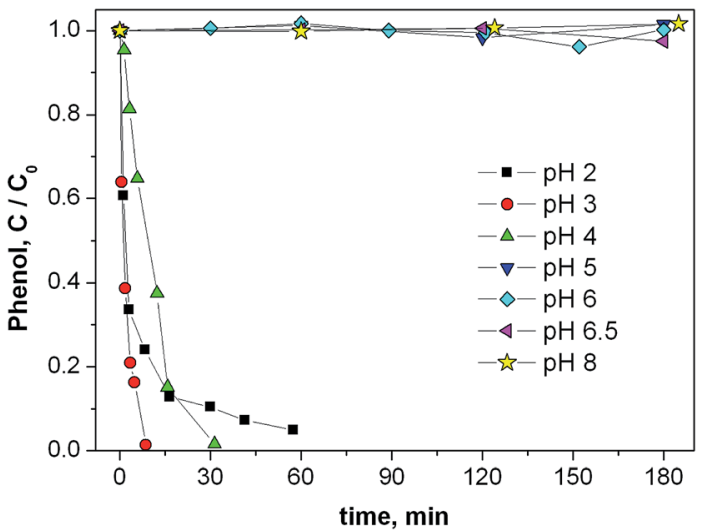

Fig. 3 Time trend of phenol (initial concentration $0.1 \mathrm{mM}$ ) in the presence of $1 \mathrm{mM} \mathrm{H}_{2} \mathrm{O}_{2}$ and $0.1 \mathrm{~g} \mathrm{~L}^{-1} \mathrm{pZVI}$ at different $\mathrm{pH}$ values, adjusted by addition of $\mathrm{HClO}_{4}$. The error bars are not reported on this or other plots for a sake of readability. The reproducibility among repeated experiments was in the range of $10-20 \%$.

at least to a certain extent, the Fenton process in $\mathrm{O}_{2}$-containing solutions through reactions (2-8), without $\mathrm{H}_{2} \mathrm{O}_{2}$ addition. ${ }^{23,24}$ However, the extent by which the Fenton reaction is triggered in this way is expected to be lower compared to the process started by $\mathrm{H}_{2} \mathrm{O}_{2}$ addition, because the low amount of in situ generated $\mathrm{H}_{2} \mathrm{O}_{2}$ is the most limiting factor. ${ }^{5}$ Moreover, pZVI has almost no intact $\mathrm{Fe}^{0}$ sites that can promote the formation of $\mathrm{H}_{2} \mathrm{O}_{2}$, which explains the lack of phenol degradation by pZVI without $\mathrm{H}_{2} \mathrm{O}_{2}$.

In contrast, phenol was degraded in the presence of pZVI + $\mathrm{H}_{2} \mathrm{O}_{2}$ (Fig. 4) and the degradation was most efficient for a $\mathrm{H}_{2} \mathrm{O}_{2}$ concentration level around $1 \mathrm{mM}$. Lower $\mathrm{H}_{2} \mathrm{O}_{2}$ values would reduce the rate by which reactive oxidizing species are generated, while higher concentrations would entail a significant scavenging of reactive species by $\mathrm{H}_{2} \mathrm{O}_{2}$ itself (hydrogen peroxide is able to scavenge ${ }^{\circ} \mathrm{OH}$ with a second-order reaction rate constant of $\left.2.7 \times 10^{7} \mathrm{M}^{-1} \mathrm{~s}^{-1}\right) .{ }^{61}$

The $1 \mathrm{mM} \mathrm{H}_{2} \mathrm{O}_{2}$ concentration that induces very fast and complete removal of $0.1 \mathrm{mM}$ phenol is stoichiometrically insufficient to achieve total mineralization, because the

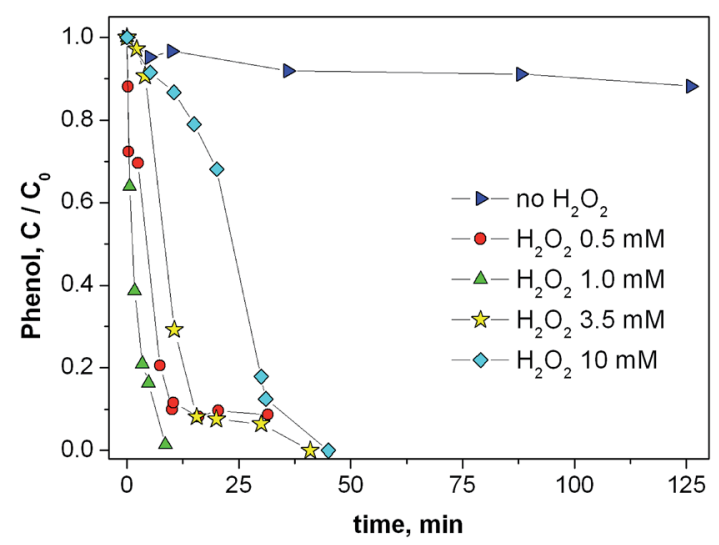

Fig. 4 Time trend of phenol (initial concentration $0.1 \mathrm{mM}$ ) in the presence of $0.1 \mathrm{~g} \mathrm{~L}^{-1} \mathrm{pZVI}$ at $\mathrm{pH} 3$, adjusted by addition of $\mathrm{HClO}_{4}$, with different concentration values of $\mathrm{H}_{2} \mathrm{O}_{2}$. 
transformation of a phenol molecule into six $\mathrm{CO}_{2}$ molecules requires the abstraction of 28 electrons. Since $\mathrm{H}_{2} \mathrm{O}_{2}$ is a 2electron oxidant, the mineralization of a phenol molecule would require at least $14 \mathrm{H}_{2} \mathrm{O}_{2}$. Therefore, the $10: 1 \mathrm{H}_{2} \mathrm{O}_{2}$ :phenol ratio used here is not enough to mineralize phenol if $\mathrm{H}_{2} \mathrm{O}_{2}$ is the only oxidant species. Such a scenario is modified by the fact that $\mathrm{H}_{2} \mathrm{O}_{2}$ is activated to produce ${ }^{\circ} \mathrm{OH}$ and that additional redox reactions between radical species (formed from phenol $+{ }^{\circ} \mathrm{OH}$ ) and dissolved $\mathrm{O}_{2}$ would also contribute to the oxidation process. ${ }^{62}$ The time trend of the TOC was monitored at pH 3 in the presence of $0.1 \mathrm{mM}$ phenol (corresponding to an initial TOC of $7.2 \mathrm{mg} \mathrm{C} \mathrm{L}^{-1}$ ), of $0.1 \mathrm{~g} \mathrm{~L}^{-1} \mathrm{pZVI}$ and, in separate experiments, of $1,3.5$ and $10 \mathrm{mM} \mathrm{H}_{2} \mathrm{O}_{2}$. In the case of $1 \mathrm{mM}$ $\mathrm{H}_{2} \mathrm{O}_{2}$, the TOC decreased by around $2 \mathrm{mg} \mathrm{C} \mathrm{L}^{-1}$ (corresponding to $25-30 \%$ of mineralization) in $1 \mathrm{~h}$ reaction time and then remained approximately constant. The observed degree of mineralization was considerably lower than the theoretical value of $\sim 70 \%$ that would be obtained by purely stoichiometric considerations. Insignificant mineralization was then observed with 3.5 and $10 \mathrm{mM} \mathrm{H} \mathrm{H}_{2} \mathrm{O}_{2}$, thereby suggesting that the improvement of the oxidation stoichiometry (due to a higher $\mathrm{H}_{2} \mathrm{O}_{2}$ : phenol ratio) was largely offset by the scavenging of reactive species carried out by $\mathrm{H}_{2} \mathrm{O}_{2}$.

Overall, the Fenton reaction catalyzed by pZVI appears to be a potentially effective way to induce the degradation of the primary substrate, but not to achieve total mineralization. However, in several practical applications the pollutants occur in the aqueous phase together with dissolved organic matter (DOM), and the target of total mineralization would also entail the unnecessary transformation of DOM into $\mathrm{CO}_{2}$. In such a case, the selective mineralization of the pollutant(s) could be non attainable or, in any case, not experimentally verifiable. Still, in the absence of mineralization one should take into account the potential health effects and environmental fate of the reaction mixture. ${ }^{63}$ The case of phenol is not problematic because it is not difficult to avoid the formation of possibly toxic intermediates by controlling the Fenton operational conditions. ${ }^{64}$ Moreover, the biodegradability of xenobiotics often increases significantly during the first oxidative (Fenton) steps, although mineralization may not be achieved, and a combined process with a biological post-treatment is an interesting option. ${ }^{65}$ However, the harmful effects of the transformation intermediates may be very important for some pollutants, and the suitability of pZVI-Fenton as treatment system should be checked case by case, depending on the substrate to be degraded.

3.1.3. Time trends of $\mathrm{H}_{2} \mathrm{O}_{2}$ and dissolved Fe. The rationale of these experiments is two-fold. On the one hand the release of Fe in solution could trigger a homogeneous Fenton process, thereby contributing to the degradation reactions, but the occurrence of dissolved Fe may be problematic for some applications. Fe dissolution may be a minor issue in soil and groundwater remediation but, in a different technological context, in several countries the effluents with more than $1 \mathrm{mg}$ $\mathrm{L}^{-1}$ dissolved Fe cannot be discharged into surface waters. ${ }^{66}$ The monitoring of the time trend of $\mathrm{H}_{2} \mathrm{O}_{2}$ is also important, because it affects the speciation of dissolved Fe.

The experiments were carried out at several values of $\mathrm{pH}$ and $\mathrm{H}_{2} \mathrm{O}_{2}$ concentration, in the presence of $0.1 \mathrm{mM}$ phenol and $0.1 \mathrm{~g}$ $\mathrm{L}^{-1}$ pZVI. Fig. 5A and $\mathrm{B}$ reports the results obtained at $\mathrm{pH} 2$, with $\mathrm{H}_{2} \mathrm{O}_{2} 1 \mathrm{mM}$ (Fig. 5A) and $3.5 \mathrm{mM}$ (Fig. 5B). In the former case, $\mathrm{H}_{2} \mathrm{O}_{2}$ concentration halved very quickly and hydrogen
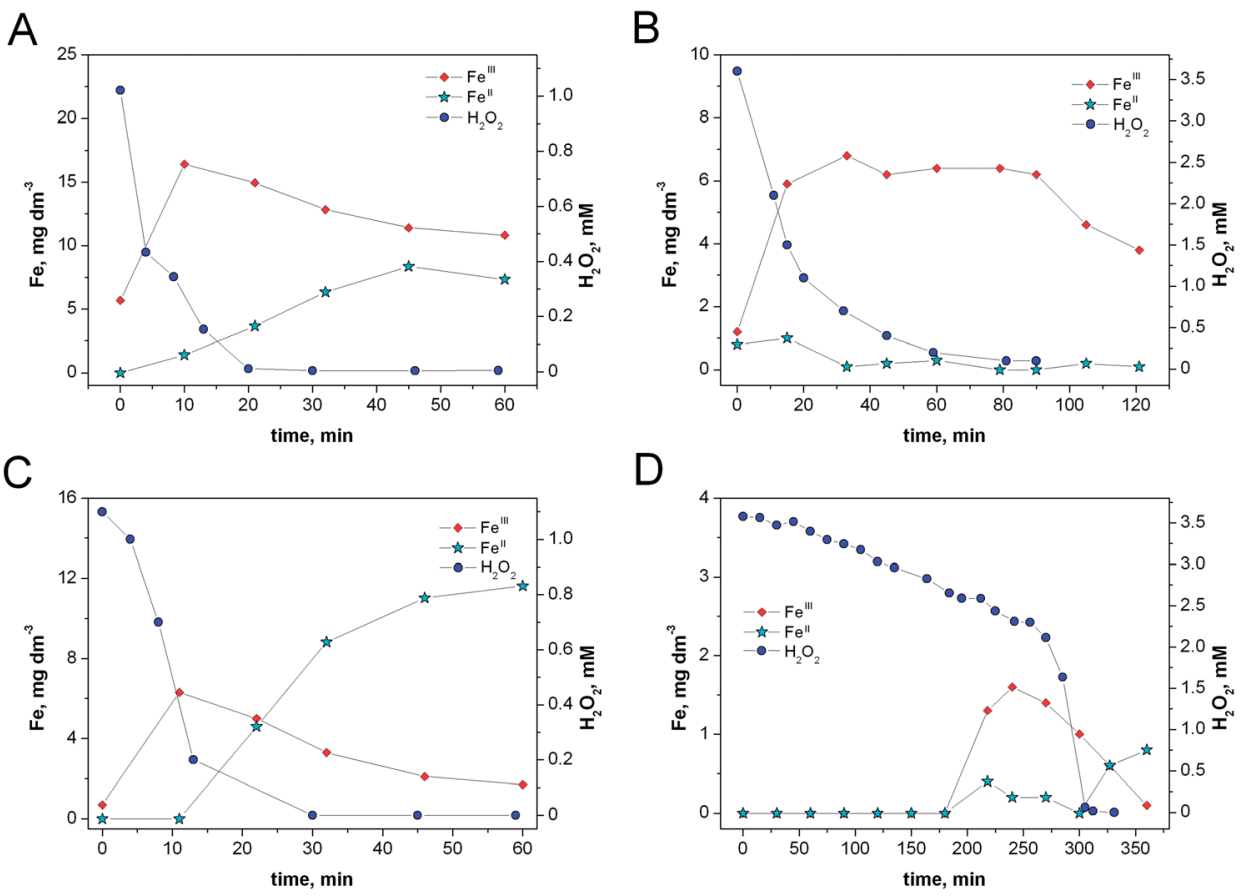

Fig. 5 Time trends of $\mathrm{Fe}^{\mathrm{III}}$, $\mathrm{Fe}^{\mathrm{II}}$ (left $Y$-axis) and $\mathrm{H}_{2} \mathrm{O}_{2}$ (right $Y$-axis), in the presence of $0.1 \mathrm{mM}$ phenol, $0.1 \mathrm{~g} \mathrm{~L}^{-1} \mathrm{pZVl}$, and: (A) $1 \mathrm{mM} \mathrm{H} \mathrm{O}_{2}$ at $\mathrm{pH} 2$; (B) $3.5 \mathrm{mM} \mathrm{H}_{2} \mathrm{O}_{2}$ at $\mathrm{pH}$ 2; (C) $1 \mathrm{mM} \mathrm{H}_{2} \mathrm{O}_{2}$ at $\mathrm{pH}$ 3; (D) $3.5 \mathrm{mM} \mathrm{H}_{2} \mathrm{O}_{2}$ at $\mathrm{pH}$ 3. The $\mathrm{pH}$ values were adjusted by addition of $\mathrm{HClO}_{4}$. 
peroxide became undetectable after $20 \mathrm{~min}$. The $\mathrm{Fe}^{\mathrm{III}}$ concentration peaked at around $10 \mathrm{~min}$ reaction time, while $\mathrm{Fe}^{\mathrm{II}}$ increased up to $45 \mathrm{~min}$. The initial strong prevalence of $\mathrm{Fe}^{\mathrm{III}}$ over $\mathrm{Fe}^{\mathrm{II}}$ is accounted for by the occurrence of residual $\mathrm{H}_{2} \mathrm{O}_{2}$, which oxidizes $\mathrm{Fe}^{\mathrm{II}}$ to $\mathrm{Fe}^{\mathrm{III}}$ (reaction (7)). The $\mathrm{Fe}^{\mathrm{II}}$ oxidation process is expected to stop after the disappearance of $\mathrm{H}_{2} \mathrm{O}_{2}$, coherently with the time trend of the Fe species. Fig. 5B shows that $3.5 \mathrm{mM} \mathrm{H}_{2} \mathrm{O}_{2}$ took longer to disappear from the system ( $\sim 90 \mathrm{~min}$ ) than $1 \mathrm{mM} \mathrm{H}_{2} \mathrm{O}_{2}(\sim 20 \mathrm{~min})$. Coherently, with $3.5 \mathrm{mM}$ $\mathrm{H}_{2} \mathrm{O}_{2}$ the $\mathrm{Fe}^{\mathrm{III}}$ levels were initially much higher than those of $\mathrm{Fe}^{\mathrm{II}}$ and started decreasing only after $\sim 90$ min reaction time.

At $\mathrm{pH} 3$ the concentration of dissolved $\mathrm{Fe}^{\mathrm{III}}$ was lower than at pH 2 (see Fig. 5C and D), which is consistent with a decrease of the $\mathrm{Fe}^{\mathrm{III}}$ solubility with increasing $\mathrm{pH} .^{55,56}$ In the presence of 1 $\mathrm{mM} \mathrm{H} \mathrm{H}_{2} \mathrm{O}_{2}$ at $\mathrm{pH} 3$ (Fig. $5 \mathrm{C}$ ), $\mathrm{Fe}^{\mathrm{III}}$ was the main dissolved $\mathrm{Fe}$ species for reaction times $<20 \mathrm{~min}$, when $\mathrm{H}_{2} \mathrm{O}_{2}$ was still detectable. Moreover, the build-up of $\mathrm{Fe}^{\mathrm{II}}$ with time is consistent with the disappearance of $\mathrm{H}_{2} \mathrm{O}_{2}$. The decrease of dissolved $\mathrm{Fe}^{\mathrm{III}}$ after 10 min reaction time could be due to precipitation on the solid, reduction to $\mathrm{Fe}^{\mathrm{II}}$, or both. In the case of $3.5 \mathrm{mM} \mathrm{H}_{2} \mathrm{O}_{2}$, which became undetectable after $300 \mathrm{~min}$, the level of dissolved $\mathrm{Fe}^{\mathrm{III}}$ was higher than that of $\mathrm{Fe}^{\mathrm{II}}$ until $\mathrm{H}_{2} \mathrm{O}_{2}$ disappearance (Fig. 5D).

At $\mathrm{pH} 4$ or higher, dissolved Fe could not be detected in either oxidation state, which is again consistent with a decreasing solubility of the Fe species with increasing $\mathrm{pH}$. At $\mathrm{pH}$ 4, phenol disappeared within $30 \mathrm{~min}$ reaction time in the presence of pZVI $+1 \mathrm{mM} \mathrm{H}_{2} \mathrm{O}_{2}$ (see Fig. 3), thereby suggesting that the reaction took place independently of the occurrence of dissolved Fe. The latter inference is further supported by the fact that phenol disappeared in about $40 \mathrm{~min}$ in the presence of $3.5 \mathrm{mM} \mathrm{H}_{2} \mathrm{O}_{2}$ at $\mathrm{pH} 3$ (see Fig. 4), at which reaction time the dissolved Fe was still below detection limit (see Fig. 5D). These findings suggest that a homogeneous-phase reaction between $\mathrm{H}_{2} \mathrm{O}_{2}$ and dissolved $\mathrm{Fe}$ may not be necessary to trigger the degradation of phenol. In contrast, a reaction of $\mathrm{H}_{2} \mathrm{O}_{2}$ with the pZVI surface should be invoked to account for the observed results.

To further stress the above point, phenol degradation was studied in the presence of $1 \mathrm{mM} \mathrm{H}_{2} \mathrm{O}_{2}$ at $\mathrm{pH} 2$ and 3 in the homogeneous phase, without pZVI but with comparable levels of dissolved Fe as those detected in the pZVI runs (see Fig. 1 in the ESI; $\dagger$ homogeneous Fe was obtained by dissolution of $\mathrm{FeSO}_{4}$ or $\left.\mathrm{Fe}\left(\mathrm{NO}_{3}\right)_{3}\right)$. The homogeneous-phase experiment at $\mathrm{pH} 3$ was carried out in the presence of $6 \mathrm{mg} \mathrm{L}^{-1}$ dissolved $\mathrm{Fe}^{\mathrm{III}}$, because in the corresponding pZVI run the dissolved $\mathrm{Fe}^{\mathrm{II}}$ was still undetectable by the time phenol underwent complete degradation. The results of the homogeneous-phase experiments showed that phenol degradation with dissolved $\mathrm{Fe}+\mathrm{H}_{2} \mathrm{O}_{2}$ was always considerably slower compared to pZVI $+\mathrm{H}_{2} \mathrm{O}_{2}$. Therefore, it is suggested that the pZVI-Fenton process involves reaction between $\mathrm{H}_{2} \mathrm{O}_{2}$ and either the pZVI surface or iron species located in the interfacial double layer of the colloidal particles, to a higher extent than reaction of $\mathrm{H}_{2} \mathrm{O}_{2}$ with dissolved Fe species in the solution bulk.

Coming back to the results shown in Fig. 5, it appears that dissolved Fe in the pZVI runs at pH 2 and 3 easily reached levels higher than $1 \mathrm{mg} \mathrm{Fe} \mathrm{L}^{-1}$. Therefore, in contexts where dissolved Fe levels above $1 \mathrm{mg} \mathrm{Fe} \mathrm{L}^{-1}$ may be a problem (e.g. for discharge of wastewater into receiving water bodies), operation at $\mathrm{pH} 4$ that gave leached $\mathrm{Fe}<0.05 \mathrm{mg} \mathrm{L}^{-1}$ could be a good compromise to achieve pollutant degradation with limited Fe release.

3.1.4. Effect of the ageing time of PZVI in aqueous suspension. In order to simulate the impact of the residence time in a groundwater system or in a chemical treatment reactor, pZVI particles were aged in oxygen-containing water (open bottle equilibrated with air) for up to one month at the natural pH (around 8). The ability of pZVI to promote the Fenton oxidation of phenol was then studied as a function of the ageing time. First, change in visual appearance of the pZVI suspensions was observed from a few days of ageing time, which was further confirmed by monitoring of the extinction spectra (see Fig. 2 ESI $\dagger$ ). As explained above, the pZVI sample exhibits wide particle size heterogeneity $(\sim 20 \mathrm{~nm}$ to $\sim 200 \mathrm{~nm}$, with some particles reaching up to $\sim 2 \mu \mathrm{m})$. The behavior of particles upon ageing in water or oxidation, as well as their reactivity is expected to strongly depend on the particle size or surface-to-volume ratio. It is known that the iron (hydr)oxide layer coating the ZVI particles has a thickness of several nanometers, and the oxidation (or the reactivity) of nano-sized particles (high exposed surface area) is more important than for micro-sized ones. ${ }^{9}$ As a matter of fact, nano-scale ZVI particles, spherical in shape, can be completely transformed into ferrihydrite then lepidocrocite in less than two hours in oxygen-containing water, as recently shown by $\mathrm{He}$ et $a .^{67}$ Formation of magnetite $\left(\mathrm{Fe}_{3} \mathrm{O}_{4}\right)$ seemed to be thermodynamically favorable during a decontamination reaction using ZVI at circumneutral $\mathrm{pH}^{\mathbf{6 8 , 6 9}}$ In addition, goethite $(\alpha-\mathrm{FeOOH})$ and hematite $\left(\alpha-\mathrm{Fe}_{2} \mathrm{O}_{3}\right)$ have been also detected as oxidation byproducts of ZVI in water depending on $\mathrm{pH}$, solution chemistry and type of ZVI. ${ }^{70-72}$

Given the higher reactivity of nanosized minerals, ${ }^{73}$ we can suppose that a rapid oxidation of very small particles may first occur in our pZVI suspensions having a broad particle size distribution. This is confirmed by TEM analysis of the wateraged sample, where we can observe some needles (acicularlike particles) (Fig. 2) which may correspond to lepidocrocite or goethite that generally have this form in aqueous suspension. ${ }^{74}$ However, formation of $\mathrm{Fe}^{\mathrm{III}} \mathrm{OOH}$ could not be identified by XRD (Fig. 1), probably because of its very low amount with respect to the bulk metallic phase $(\alpha-\mathrm{Fe})$. Indeed, the proportion of very small particles is supposed to be relatively low according to the particle size analysis. ${ }^{34}$

These observations suggest that particles in pZVI suspensions may have different behaviors towards oxidation, and that ageing in aqueous suspension (under open air atmosphere) may essentially oxidize the smallest particles (the most reactive ones) to $\mathrm{Fe}^{\mathrm{III}} \mathrm{OOH}$, as previously observed for nano-sized $\mathrm{ZVI}$ particles. ${ }^{67}$ This may modify the surface charge of particles in pZVI suspensions, thereby altering the electrostatic interactions between the different kinds of particles, as well as the aggregation state in the suspensions (as previously mentioned, see Fig. 2 ESI $\dagger$ ). 
A

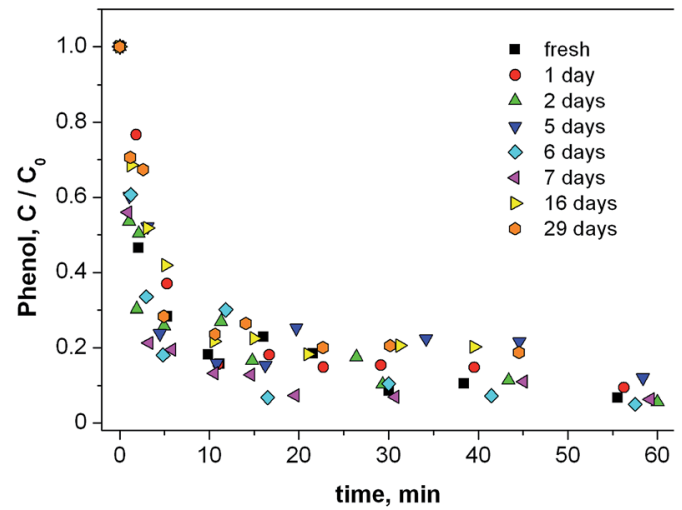

B

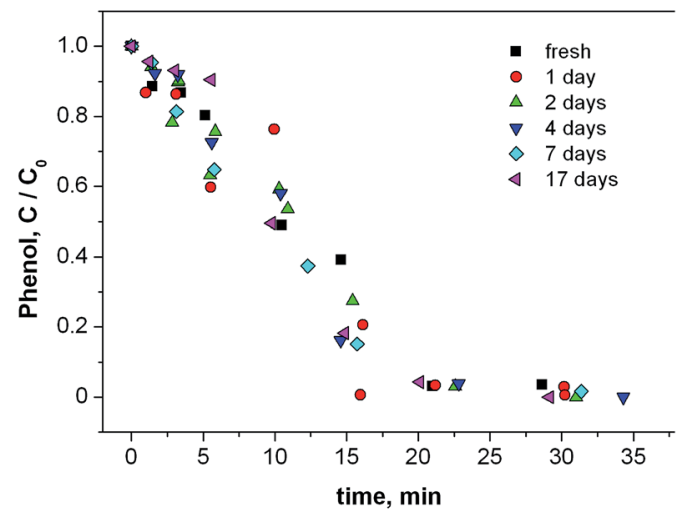

C

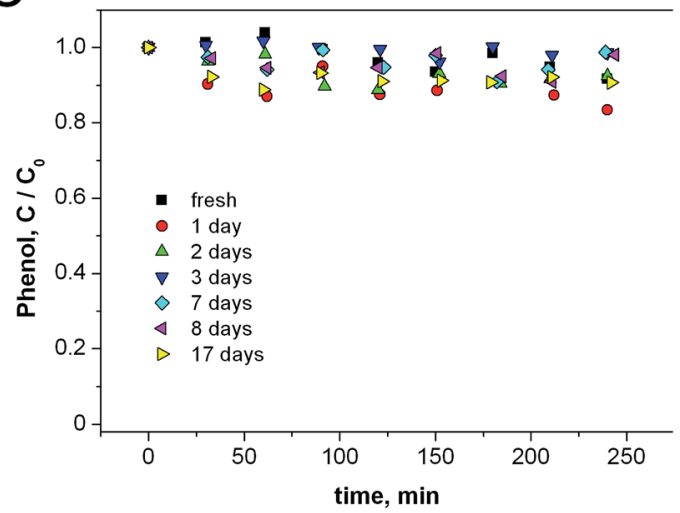

Fig. 6 Time trend of phenol (initial concentration $0.1 \mathrm{mM}$ ) in the presence of $1 \mathrm{mM} \mathrm{H}_{2} \mathrm{O}_{2}$ and $0.1 \mathrm{~g} \mathrm{~L}^{-1} \mathrm{pZVI}$. The pZVI stock aqueous suspension ( $1 \mathrm{~g} \mathrm{~L}^{-1}$ loading) was stored in the presence of air for the reported amount of time prior to use. (A) $\mathrm{pH}$ 2; (B) $\mathrm{pH} 4$; (C) $\mathrm{pH}$ 6. The $\mathrm{pH}$ values were adjusted by addition of $\mathrm{HClO}_{4}$.

The influence of the storage time on the Fenton reactivity of pZVI was tested at different $\mathrm{pH}$ values, using phenol as model molecule. Fig. 6 shows the time trend of $0.1 \mathrm{mM}$ phenol in the presence of $0.1 \mathrm{~g} \mathrm{~L}^{-1}$ pZVI and $1 \mathrm{mM} \mathrm{H}_{2} \mathrm{O}_{2}$, at pH 2 (Fig. 6A), 4 (Fig. 6B) and 6 (Fig. 6C). A test at pH 3 is not reported, because the elevated pZVI reactivity caused very fast degradation of phenol and made it very difficult to highlight small differences between degradation experiments.

The runs at $\mathrm{pH} 2$ did not show a trend as a function of the ageing time. Small differences between experiments are likely accounted for by random variability, independently of ageing. A similar issue was observed at $\mathrm{pH} 4$; finally, insignificant phenol degradation took place at $\mathrm{pH} 6$ in the presence of pZVI and $\mathrm{H}_{2} \mathrm{O}_{2}$. The runs at $\mathrm{pH} 6$, where pZVI was practically non-reactive, give insight into the overall variability concerning the monitoring of phenol concentration. These results strengthen the interpretation given to the data obtained at pH 2 and 4, namely that the limited variations observed in different experiments were not due to ageing but to experimental repeatability issues.

The Fenton reactivity of pZVI was thus not affected by the ageing of particles in $\mathrm{O}_{2}$-containing water. While the ageing process may entirely transform nanosized particles into $\mathrm{Fe}^{\mathrm{III}}$ oxides in aerated water, ${ }^{67}$ only an outer coating layer may be formed on microsized ZVI surfaces upon oxidation. Experimental evidences of these mineralogical transformations are hard to obtain, particularly in pZVI suspension with broad particle size heterogeneity. The oxidation by-products of ZVI or the passivated layer formed on ZVI surfaces are generally composed of magnetite, maghemite, goethite, lepidocrocite and/or hematite. ${ }^{67-72}$ The latter may have different reactivities for the Fenton reaction, as the $\mathrm{Fe}^{\mathrm{II}}-\mathrm{Fe}^{\mathrm{III}}$ mixed valence oxides are known to be more effective than only $\mathrm{Fe}^{\mathrm{III}}$ oxides, ${ }^{75}$ which are expected to be formed preferentially from the smaller particles. ${ }^{67}$ In addition, the $\mathrm{Fe}^{\mathrm{II}} / \mathrm{Fe}^{\mathrm{III}}$ ratio in mixed oxides considerably affects the intrinsic reactivity for the Fenton or photo-Fenton oxidation. ${ }^{39,76}$ Therefore, it is possible that different processes taking place during ageing compensate for each other as far as the Fenton reactivity of pZVI is concerned.

\subsection{Photo-Fenton reactivity of pZVI at higher $\mathrm{pH}$ values under UVA irradiation}

Phenol degradation by pZVI $+\mathrm{H}_{2} \mathrm{O}_{2}$ was also studied under irradiation. The dark Fenton reactivity of pZVI at pH 4 or lower

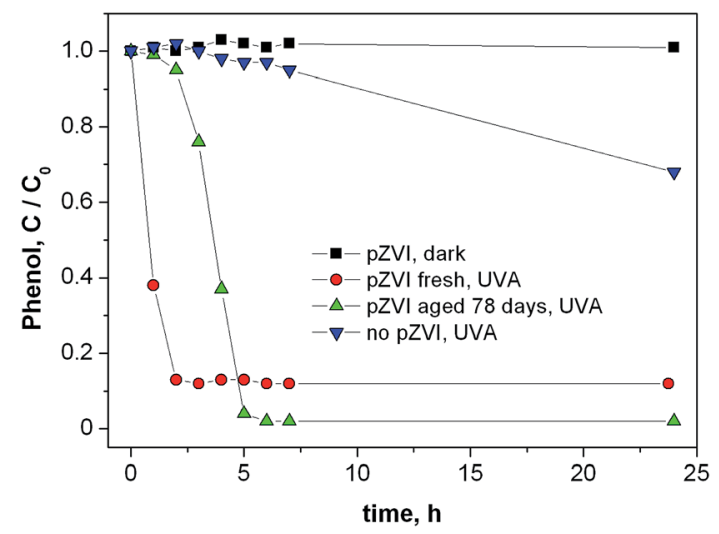

Fig. 7 Time trend of phenol (initial concentration $0.1 \mathrm{mM}$ ) in the presence of $1 \mathrm{mM} \mathrm{H}_{2} \mathrm{O}_{2}$ and, according to the different experiments (see figure legend): ( $\mathbf{a})$ fresh pZVI $\left(0.1 \mathrm{~g} \mathrm{~L}^{-1}\right.$ ) in the dark ("fresh pZVI" denotes the material that underwent initial ageing in air but did not undergo additional ageing in aqueous suspension); (O) fresh pZVI (0.1 $\mathrm{g} \mathrm{L}^{-1}$ ) under UVA irradiation; ( $\left.\mathbf{\Delta}\right)$ aged $\mathrm{pZVI}\left(0.1 \mathrm{~g} \mathrm{~L}^{-1}\right)$ under UVA irradiation (this material was aged in aqueous suspension for 78 days), and $(\boldsymbol{\nabla})$ no $\mathrm{pZVI}$ under UVA irradiation. In all the experiments the $\mathrm{pH}$ value was 5, adjusted with $\mathrm{HClO}_{4}$. 
is obviously a confounding factor for the irradiation experiments, which were thus carried out at pH 5 or higher where the dark reactions are not operational. Fig. 7 shows the time trend of phenol at pH 5 (by $\mathrm{HClO}_{4}$ ) in the presence of pZVI $+\mathrm{H}_{2} \mathrm{O}_{2}$ in the dark, of $\mathrm{H}_{2} \mathrm{O}_{2}$ under irradiation, and of $\mathrm{pZVI}+\mathrm{H}_{2} \mathrm{O}_{2}$ under irradiation. In the latter case, two pZVI suspensions were tested: one was freshly prepared, and the other was aged for 78 days before use. As already explained, ageing of pZVI took place in an air-equilibrated suspension. No dark reactivity could be highlighted at $\mathrm{pH}$ 5, as expected, while the limited phenol degradation with irradiated $\mathrm{H}_{2} \mathrm{O}_{2}$ (without pZVI) would be accounted for by the direct photolysis of hydrogen peroxide to give ${ }^{\circ} \mathrm{OH} .{ }^{77,78}$ Significant phenol degradation was achieved with pZVI $+\mathrm{H}_{2} \mathrm{O}_{2}$ under irradiation, with an interesting difference between the two pZVI suspensions. Degradation was initially faster with the freshly prepared pZVI, but complete phenol disappearance was not achieved. In contrast, total phenol removal was obtained with the $78 \mathrm{~d}$-aged pZVI suspension, despite the slower initial degradation stage.

The reactivity of pZVI under irradiation in the presence of $\mathrm{H}_{2} \mathrm{O}_{2}$ could be due to three main factors: (i) the photolysis of $=\mathrm{Fe}^{\mathrm{III}}-\mathrm{OH}$ surface groups to produce ${ }^{\circ} \mathrm{OH}$ and $\mathrm{Fe}^{\mathrm{II}}$; (ii) the photolysis of $\mathrm{H}_{2} \mathrm{O}_{2}$ and, last but not least, (iii) the Fenton reaction involving either surface-bound or dissolved $\mathrm{Fe}^{\mathrm{II}}$. Due to the low solubility of Fe-oxides and low release of Fe ions at high $\mathrm{pH}$ values, no dissolved Fe (either ferrous or ferric ion) was detected in PZVI suspensions at pH 5.

When considering the different behavior of the two pZVI samples, we can suppose that the availability and reactivity of Fe-surface groups can vary with the ageing time in aqueous suspension. ${ }^{79}$ Indeed, the reaction shows a short initial lagphase in the $78 \mathrm{~d}$-aged pZVI suspension, but with higher eventual removal compared to the fresh pZVI suspension. As explained above, ageing in aerated water may mainly oxidize the smallest particles (the most reactive) to $\mathrm{Fe}^{\mathrm{III}}$-oxihydroxides, and then modify the aggregation state (i.e. exposed surface area of particles) in pZVI suspensions. This modification might induce changes in the availability of $=\mathrm{Fe}^{\mathrm{III}}-\mathrm{OH}$ surface sites in suspension, which are potential photoactive groups under UVA irradiation. ${ }^{43}$ If we make the reasonable hypothesis that the fresh pZVI surface contains a mixture of $\mathrm{Fe}^{\mathrm{II}}$ and $\mathrm{Fe}^{\mathrm{III}}$, while aged pZVI is more extensively oxidized with a prevalence of $\mathrm{Fe}^{\mathrm{III}}$ groups, the fact that aged pZVI induced complete photooxidation of phenol could be accounted for by the occurrence of a higher amount of photoactive $\mathrm{Fe}^{\mathrm{III}}$ compared to fresh pZVI, while $\mathrm{Fe}^{\mathrm{II}}$ (higher in fresh pZVI) is ineffective in the presence of $\mathrm{H}_{2} \mathrm{O}_{2}$ at $\mathrm{pH}$. The initially higher photoreactivity of fresh pZVI could be linked to the fact that the occurrence of $\mathrm{Fe}^{\mathrm{II}}$ produces a magnetite-like surface, and magnetite shows a higher activity under photo-Fenton conditions at $\sim$ neutral $\mathrm{pH}$ compared to a pure $\mathrm{Fe}^{\mathrm{III}}$ phase (e.g. hematite). ${ }^{39,80}$

Irradiation of phenol with pZVI $+\mathrm{H}_{2} \mathrm{O}_{2}$ was also carried out at $\mathrm{pH} 6$, and negligible degradation could be observed under such conditions. Compared to the absence of degradation with irradiated pZVI $+\mathrm{H}_{2} \mathrm{O}_{2}$ at $\mathrm{pH}$ 6, some phenol degradation at the same $\mathrm{pH}$ was observed with irradiated $\mathrm{H}_{2} \mathrm{O}_{2}$ alone, without $\mathrm{pZVI}$ ( $\sim 20 \%$ of the initial phenol was degraded in $24 \mathrm{~h}$ ). The most likely explanation is that, at $\mathrm{pH} 6$, inactive pZVI just shields radiation that is no longer available for $\mathrm{H}_{2} \mathrm{O}_{2}$ photolysis. It can thus be concluded that pZVI is inactive in the dark Fenton process above $\mathrm{pH} 4$, and photochemically inactive above $\mathrm{pH} 5$. The extension towards higher $\mathrm{pH}$ values of the applicability of the photo-Fenton reaction, compared to the dark Fenton process, is consistent with previous reports. ${ }^{81}$

\section{Conclusions}

The pZVI sample studied in this work had lost, due to passivation, its reduction capability as tested towards the dechlorination of chlorophenols. In contrast, it had significant Fenton and photo-Fenton (oxidizing) reactivity in the presence of $\mathrm{H}_{2} \mathrm{O}_{2}$. The dark pZVI-Fenton process, tested against the degradation of phenol, was most effective at $\mathrm{pH} 3$ but it was no longer operational at pH 5 or higher. The presence of $\mathrm{H}_{2} \mathrm{O}_{2}$ was essential to trigger reactivity up to an optimum concentration $\left(1 \mathrm{mM} \mathrm{H}_{2} \mathrm{O}_{2}\right.$ in the presence of $0.1 \mathrm{mM}$ phenol and $0.1 \mathrm{~g} \mathrm{~L}^{-1} \mathrm{pZVI}$ at $\mathrm{pH} 3$ ). Above the optimum $\mathrm{H}_{2} \mathrm{O}_{2}$ concentration the degradation of phenol became gradually less effective, presumably because of the scavenging of reactive species by $\mathrm{H}_{2} \mathrm{O}_{2}$ itself.

The pZVI-Fenton reaction occurred along with the dissolution of Fe species at $\mathrm{pH}<4$. In particular, $\mathrm{Fe}^{\mathrm{III}}$ prevailed in the dissolved phase until $\mathrm{H}_{2} \mathrm{O}_{2}$ was totally consumed, while the $\mathrm{H}_{2} \mathrm{O}_{2}$ disappearance allowed the build-up of $\mathrm{Fe}^{\mathrm{II}}$. Despite phenol degradation, no dissolved Fe was detected at $\mathrm{pH} 4$. The levels of dissolved Fe were never high enough to account for an important homogeneous Fenton process between the aqueousphase Fe species and $\mathrm{H}_{2} \mathrm{O}_{2}$. Therefore, it is hypothesized that most of phenol would be degraded either by an heterogeneous reaction between $\mathrm{H}_{2} \mathrm{O}_{2}$ and pZVI particles or immediately in the proximity of the particle surface, by the reaction of $\mathrm{H}_{2} \mathrm{O}_{2}$ with $\mathrm{Fe}^{2+}$ ions located in the interfacial double layer of the colloidal particles. The detected levels of dissolved Fe at $\mathrm{pH} 2$ and 3 were higher than $1 \mathrm{mg} \mathrm{L^{-1 }}$, which would be a problem in some possible applications such as wastewater treatment. In these cases, the operation at $\mathrm{pH} 4$ would be the best compromise between the possibility to degrade phenol and the minimization of Fe leaching. Alternatively, the use of pZVI-Fenton at $\mathrm{pH}<4$ would require additional steps to remove the excess of iron (e.g. $\mathrm{pH}$ adjustment and addition of flocculation agents).

Although an effective degradation of phenol could be achieved under several different conditions, the pZVI-Fenton system was not able to attain total mineralization. The best results (25-30\% mineralization of $0.1 \mathrm{mM}$ phenol) were obtained with $1 \mathrm{mM} \mathrm{H}_{2} \mathrm{O}_{2}$ at $\mathrm{pH}$ 3. An increase of $\mathrm{H}_{2} \mathrm{O}_{2}$ concentration, which in theory could induce a more favorable stoichiometric ratio between the oxidant and phenol, was actually detrimental. The most likely reason is the scavenging of reactive species by $\mathrm{H}_{2} \mathrm{O}_{2}$, which decreases the reactivity of the system.

The ageing time in aerated suspension, i.e. an additional forced passivation of pZVI particles in $\mathrm{O}_{2}$-containing water, did not affect the Fenton reaction performance. This remarkable catalytic stability of pZVI for a wide range of ageing times has strong implications for field applications, particularly where the 
iron slurry is injected in a groundwater portion (or engineering reactor) for a certain time.

The dark pZVI-Fenton process was inactive above $\mathrm{pH} 4$. Reactivity could be extended to $\mathrm{pH} 5$ upon UVA irradiation of the system, probably because of additional phenomena such as photolysis of $\mathrm{Fe}(\mathrm{III})$ (hydr)oxides and of $\mathrm{H}_{2} \mathrm{O}_{2}$. Finally, no Fenton or photo-Fenton reactivity was observed at $\mathrm{pH} 6$ or higher. Surprisingly, long term-aged ZVI exhibited a high photo-Fenton reactivity and total removal of phenol in aqueous suspension at pH 5.

The data presented here show that pZVI, which due to inactivity in reductive processes is an inert material and possibly a waste to be disposed of, can be re-used in Fenton oxidation reactions upon addition of $\mathrm{H}_{2} \mathrm{O}_{2}$. Therefore, ZVI can be employed as a reductant until it retains sufficient reactivity, and then be converted into a catalyst for oxidative processes in the presence of $\mathrm{H}_{2} \mathrm{O}_{2}$. The possibility to reuse a waste makes pZVI a potentially very cheap Fenton reactant.

\section{References}

1 F. He, D. Y. Zhao and C. Paul, Water Res., 2010, 44, 23602370.

2 B. Lai, Y. H. Zhang, R. Li, Y. X. Zhou and J. L. Wang, Chem. Eng. J., 2014, 249, 143-152.

3 P. Mueller, K. E. Lorber, R. Mischitz and C. Weiss, Sci. Total Environ., 2014, 485, 748-754.

4 S. Klas and D. W. Kirk, J. Hazard. Mater., 2013, 252, 77-82.

5 F. L. Fu, D. D. Dionysiou and H. Liu, J. Hazard. Mater., 2014, 267, 194-205.

6 C. B. Wenk, R. Kaegi and S. J. Hug, Environ. Chem., 2014, 11, 547-557.

7 M. J. Alowitz and M. M. Scherer, Environ. Sci. Technol., 2002, 36, 299-306.

8 S. Bae and W. Lee, Environ. Sci. Technol., 2014, 48, 23682376.

9 G. V. Lowry and K. M. Johnson, Environ. Sci. Technol., 2004, 38, 5208-5216.

10 W. Yan, R. Vasic, A. I. Frenkel and B. E. Koel, Environ. Sci. Technol., 2012, 46, 7018-7026.

11 X.-Q. Li, J. Cao and W.-X. Zhang, Ind. Eng. Chem. Res., 2008, 47, 2131-2139.

12 A. Ryu, S.-W. Jeong, A. Jang and H. Choi, Appl. Catal., B, 2011, 105, 128-135.

13 G. Sheng, X. Shao, Y. Li, J. Li, H. Dong, W. Cheng, X. Gao and Y. Huang, J. Phys. Chem. A, 2014, 118, 2952-2958.

14 H. Song and E. R. Carraway, Environ. Sci. Technol., 2005, 39, 6237-6245.

15 J. Dong, Y. Zhao, R. Zhao and R. Zhou, J. Environ. Sci., 2010, 22, 1741-1747.

16 L. J. Matheson and P. G. Tratnyek, Environ. Sci. Technol., 1994, 28, 2045-2053.

17 J. Klausen, P. J. Vikesland, T. Kohn, D. R. Burris, W. P. Ball and A. L. Roberts, Environ. Sci. Technol., 2003, 37, 1208-1218.

18 X. H. Guan, Y. K. Sun, H. J. Qin, J. X. Li, I. M. C. Lo, D. He and H. R. Dong, Water Res., 2015, 75, 224-248.
19 A. F. Orozco, M. Velimirovic, T. Tosco, A. Kemna, H. Sapion, N. Klaas, R. Sethi and L. Bastiaens, Environ. Sci. Technol., 2015, 49, 5593-5600.

20 E. Dalla Vecchia, M. Luna and R. Sethi, Environ. Sci. Technol., 2009, 43, 8942-8947.

21 S. Comba, D. Dalmazzo, E. Santagata and R. Sethi, J. Hazard. Mater., 2011, 185, 598-605.

22 H. Lee, B. H. Kim, Y. K. Park, S. J. Kim and S. C. Jung, J. Nanomater., 2015, 392537.

23 I. A. Katsoyiannis, T. Ruettimann and S. J. Hug, Environ. Sci. Technol., 2008, 42, 7424-7430.

24 H. S. Lee, H. J. Lee, H. E. Kim, J. Y. Kweon, B. D. Lee and C. H. Lee, J. Hazard. Mater., 2014, 265, 201-207.

25 C. R. Keenan and D. L. Sedlak, Environ. Sci. Technol., 2008, 42, 1262-1267.

26 S. J. Hug and O. Leupin, Environ. Sci. Technol., 2003, 37, 2734-2742.

27 S. H. Joo, A. J. Feitz and T. D. Waite, Environ. Sci. Technol., 2004, 38, 2242-2247.

28 A. J. Feitz, S. H. Joo, J. Guan, Q. Sun, D. L. Sedlak and T. D. Waite, Colloids Surf., A, 2005, 265, 88-94.

29 J. Filip, F. Karlický, Z. Marušák, M. Černík, M. Otyepka and R. Zbořil, J. Phys. Chem. C, 2014, 118, 13817-13825.

30 P. Mondal, S. Bhowmick, N. Jullok, W. Y. Ye, W. Van Renterghem, S. Van den Berghe and B. Van der Bruggen, J. Phys. Chem. C, 2014, 118, 21614-21621.

31 X. L. Zhang, B. L. Deng, J. Guo, Y. Wang and Y. Q. Lan, J. Environ. Manage., 2011, 92, 1328-1333.

32 Y. Segura, F. Martinez, J. A. Melero and J. L. G. Fierro, Chem. Eng. J., 2015, 269, 298-305.

33 T. X. Liu, X. Li and T. D. Waite, Environ. Sci. Technol., 2013, 47, 7350-7356.

34 T. X. Liu, X. Li and T. D. Waite, Environ. Sci. Technol., 2013, 47, 13712-13720.

35 T. X. Liu, X. Li and T. D. Waite, Environ. Sci. Technol., 2014, 48, 14564-14571.

36 L. Chen, S. Jin, P. H. Fallgren, F. Liu and P. J. S. Colberg, Water Sci. Technol., 2013, 67, 1254-1259.

37 P. V. V. V. Prasad, C. Das and A. K. Golder, Can. J. Chem. Eng., 2011, 89, 1575-1582.

38 I. Magario, F. S. García Einschlag, E. H. Rueda, J. Zygadlo and M. L. Ferreira, J. Mol. Catal. A: Chem., 2012, 352, 1-20.

39 M. Minella, G. Marchetti, E. De Laurentiis, M. Malandrino, V. Maurino, C. Minero, D. Vione and K. Hanna, Appl. Catal., B, 2014, 154, 102-109.

40 P. Avetta, A. Pensato, M. Minella, M. Malandrino, V. Maurino, C. Minero, K. Hanna and D. Vione, Environ. Sci. Technol., 2015, 49, 1043-1050.

41 S. X. Zhang, X. L. Zhao, H. Y. Niu, Y. Shi, Y. Q. Cai and G. B. Jiang, J. Hazard. Mater., 2009, 167, 560-566.

42 F. Tisa, A. A. A. Raman and W. M. A. W. Daud, J. Environ. Manage., 2014, 146, 260-275.

43 S. Gligorovski, R. Strekowski, S. Barbati and D. Vione, Chem. Rev., 2015, 115, 13051-13092.

44 AOAC International, Official Methods of Analysis of AOAC International, Gaithersburg MD, 20th edn, 2016. 
45 Y. Ito, Y. Tonogai, H. Suzuki, S. Ogawa, T. Yokoyama, T. Hashizume, H. Santo, K. I. Tanaka, K. Nishigaki and M. Iwaida, J.-Assoc. Off. Anal. Chem., 1981, 64, 1448-1452.

46 R. Cheng, J. L. Wang and W. X. Zhang, Biomed. Environ. Sci., 2007, 20, 410-413.

47 Y. H. Liu, F. L. Yang, P. L. Yue and G. H. Chen, Water Res., 2001, 35, 1887-1890.

48 B. Gunawardana, N. Singhal and P. Swedlund, Environ. Eng. Res., 2011, 16, 187-203.

49 H. Daraei and H. Kamali, J. Environ. Anal. Toxicol., 2014, 4, 228.

50 B. Sulzberger and H. Laubscher, Mar. Chem., 1995, 50, 103115.

51 C. Walling, Acc. Chem. Res., 1998, 31, 155-157.

52 H. Bataineh, O. Pestovsky and A. Bakac, Chem. Sci., 2012, 3, 1594-1599.

53 J. Gomis, R. F. Vercher, A. M. Amat, D. O. Martire, M. C. Gonzalez, A. B. Prevot, E. Montoneri, A. Arques and L. Carlos, Catal. Today, 2013, 209, 176-180.

54 C. Minero, M. Lucchiari, V. Maurino and D. Vione, RSC Adv., 2013, 3, 26443-26450.

55 M. F. Variava, T. L. Church and A. T. Harris, Appl. Catal., B, 2012, 123, 200-207.

56 C. C. Kuan, S. Y. Chang and S. L. M. Schroeder, Ind. Eng. Chem. Res., 2015, 54, 8122-8129.

57 P. Ghosh, C. Kumar, A. N. Samanta and S. Ray, J. Chem. Technol. Biotechnol., 2012, 87, 914-923.

58 C. L. Hsueh, Y. H. Huang, C. C. Wang and C. Y. Chen, Chemosphere, 2005, 58, 1409-1414.

59 U. Bali, E. Catalkaya and F. Sengul, J. Hazard. Mater., 2004, 114, 159-166.

60 M. Vilve, S. Vilhunen, M. Vepsalainen, T. A. Kurniawan, N. Lehtonen, H. Isomaki and M. Sillanpaa, Environ. Sci. Pollut. Res., 2010, 17, 875-884.

61 G. V. Buxton, C. L. Greenstock, W. P. Helman and A. B. Ross, J. Phys. Chem. Ref. Data, 1988, 17, 513-886.

62 X. Fang, X. Pan, A. Rahmann, H. P. Schuchmann and C. von Sonntag, Chem.-Eur. J., 1995, 1, 423-429.

63 L. Rizzo, Water Res., 2011, 45, 4311-4340.
64 J. A. Zazo, J. A. Casas, C. B. Molina, A. Quintanilla and J. J. Rodriguez, Environ. Sci. Technol., 2007, 41, 7164-7170.

65 S. Harimurti, B. K. Dutta, I. F. B. M. Ariff, S. Chakrabarti and D. Vione, Water, Air, Soil Pollut., 2010, 211, 273-286.

66 National Environmental Agency, Allowable limits for trade effluent discharge to sewer/watercourse/controlled watercourse, http://www.nea.gov.sg, last accessed May 2016.

67 D. He, J. Ma, R. N. Collins and T. D. Waite, Environ. Sci. Technol., 2016, 50, 3820-3828.

68 Y. Liu and G. V. Lowry, Environ. Sci. Technol., 2006, 40, 60856090.

69 S. Bae and K. Hanna, Environ. Sci. Technol., 2015, 49, 1053610543.

70 X. Q. Li and W. X. Zhang, Langmuir, 2006, 22, 4638-4642.

71 H. Luo, S. Jin, P. H. Fallgren, P. J. S. Colberg and P. A. Johnson, Chem. Eng. J., 2010, 160, 185-189.

72 S. Bae, S. Gim, H. Kim and K. Hanna, Appl. Catal., B, 2016, 182, 541-549.

73 M. F. Hochella, S. K. Lower, P. A. Maurice, R. L. Penn, N. Sahai and D. L. Sparks, Science, 2008, 319, 1631-1635.

74 R. M. Cornell and U. Schwertmann, The Iron Oxides: Structure, Properties, Reactions, Occurrences and Uses, John Wiley \& Sons, Weinheim, 2006.

75 R. Matta, K. Hanna and S. Chiron, Sci. Total Environ., 2007, 385, 242-251.

76 X. Xue, K. Hanna and N. Deng, J. Hazard. Mater., 2009, 166, 407-414.

77 G. Hurwitz, P. Pornwongthong, S. Mahendra and E. M. V. Hoek, Chem. Eng. J., 2014, 240, 235-243.

78 P. Nissenson, D. Dabdub, R. Das, V. Maurino, C. Minero and D. Vione, Atmos. Environ., 2010, 44, 4859-4866.

79 V. Sarathy, P. G. Tratnyek, J. T. Nurmi, D. R. Baer, J. E. Amonette, C. Chun, R. L. Penn and E. J. Reardon, J. Phys. Chem. C, 2008, 112, 2286-2293.

80 L. Demarchis, M. Minella, R. Nisticò, V. Maurino, C. Minero and D. Vione, J. Photochem. Photobiol., A, 2015, 307, 99-107.

81 Y. L. Wu, M. Passananti, M. Brigante, W. B. Dong and G. Mailhot, Environ. Sci. Pollut. Res., 2014, 21, 12154-12162. 